\title{
Araştırma Makalesi \\ Su Kurbağasında İribaşlarında (Rana ridibunda Pallas, 1771) Dört Ağır Metal ( Pb, Co, Ba, Cr) Tuzunun Akut Toksisitesinin Araştırılması
}

\author{
Utku Güner * \\ Department of Biology, Science Faculty, Trakya University, Edirne, Türkiye
}

Öz

Su kirliliğini oluşturan tehlikeli etkenlerden biri de ağır metallerdir. Ağır metaller, sucul ekosistemlerde eser miktarda bulunurken; atmosferik faaliyetler, jeolojik yapıların erozyonu veya antropojenik etkiler sonucu sudaki konsantrasyonlarında artış görülmektedir. $\mathrm{Bu}$ araştırmada dört farklı ağır metal $(\mathrm{Pb}, \mathrm{Co}, \mathrm{Ba}, \mathrm{Cr})$ tuzunun 96 saatlik $\mathrm{LC}_{50}$ değeri, Türkiye'de uygun habitatlarda bol miktarda gözlenen iribaşlarda (Pelophylax ridibundus Pallas, 1771) hesaplanmıştır. Deneyler kimyasal yapısı bilinen test suyunda farklı konsantrasyonda metal tuzu içeren kaplarda yapılmıştır. Deneylerde 1 litrelik kaplar içinde 0 $\mathrm{mg} / \mathrm{L}, 1 \mathrm{mg} / \mathrm{L}, 10 \mathrm{mg} / \mathrm{L}, 50 \mathrm{mg} / \mathrm{L}, 100 \mathrm{mg} / \mathrm{L}$ ve $200 \mathrm{mg} / \mathrm{L}$ ağır metal konsantrasyonlarında gerçekleştirilmiştir. Çalışma sonunda elde edilen veriler, probit analizi metodu kullanılarak değerlendirildi; sonuçta su iribaşlar için 96 saat $\mathrm{LC}_{50}$ değerleri sırasıly $\mathrm{Pb}$ 99,702; Co 69,783; Ba 62,737; Cr 30,002; mg/L olarak belirlenmiştir.

Anahtar kelimeler: Pelophylax ridibundus, iribaş, $\mathrm{LC}_{50}$

\section{Investigation of Acute Toxicity of Four Heavy Metal (Pb, Co, Ba, Cr) Salts in the Water Frog (Rana ridibunda Pallas, 1771)}

\begin{abstract}
One of the dangerous chemical of water pollution is heavy metals. Heavy metals are trace amounts in aquatic ecosystems; atmospheric activities, erosion of geological structures or anthropogenic effects increase in water concentrations. In this study four different heavy metal salts $(\mathrm{Pb}, \mathrm{Co}, \mathrm{Ba}, \mathrm{Cr})$ of the 96-hour $\mathrm{LC}_{50}$ value calculated abundantly observed in tadpole in suitable habitat in Turkey (Pelophylax ridibundus Pallas, 1771) were determined. The experiments were carried out in containers containing different concentrations of metal salt in the known test water of the chemical structure. The experiments were carried out in 1 liter containers at $0,1,10,50,100$ and $200 \mathrm{mg} / \mathrm{L}$ heavy metal concentrations. The data obtained at the end of the study were evaluated by using probit analysis method; as a result, the $\mathrm{LC}_{50}$ values for water tadpoles for 96 hours were $\mathrm{Pb}$ 99.702; Co 69.783; Ba 62.737; Cr 30.002; mg/L respectively.
\end{abstract}

Keywords: Pelophylax ridibundus, tadpole, $\mathrm{LC}_{50}$

\footnotetext{
* Sorumlu Yazar

e-mail: uguner@trakya.edu.tr
}

Received: 13.11.2018

Accepted: 20.12.2018 


\section{Giriş}

Günümüzde çevre kirliğine bağlı olarak küresel biyolojik çeşitlilikteki düşüş hızlanarak devam etmektedir. Kirliliğin etkilediği canlılardan biride iki yaşamlılardır. İki yaşamlılar, larva ve ergin evrelerinde, sucul ekosistemlerdeki kirleticilerden akut ve kronik düzeyde etkilenmektedir [1].

İki yaşamlı iribaşları pek çok bilimsel çalışmada, çevresel kirleticilerin toksisitesi belirlemek amaciyla kullanılmaktadır. Kurbağa iribaşları ve yumurtalarında yapılan FETAX (Frog Embryos Teratogenesis Assay: Xenopus) testi kimyasal maddelerin teratojenitesini saptamak üzere kullanılmaktadır [2, 3]. Ağır metaller [4, 5] ve pestisitler [6, 7] çevresel kirleticilerin başında gelmektedir. Ayrıca iribaşlar kirliliğin tespitinde biyoindikatör olarak kullanılmaktadır. Örneğin büyüme geriliği [8], uzuv yenilenmesi [9] , teratojenite [10] çeşitli toksik madde varlığ 1 ve kirlilik derecesini belirlemek için incelenmektedir.

Ağır metal kirliliği, biyolojik çeşitlilik azalmasında önemli etkendir [11]. Örneğin bakır kirliliği olan habitatlarda iki yaşamlılar popülasyonlarının azaldığı belirlenmiştir. Ayrıca farklı türlerdeki iki yaşamlarının bakırı farklı miktarda biriktirdiği belirlenmiștir [12]. Ağır metallerin iribaşlar üzerindeki akut etkileri ve ağır metal birikimi konusunda çalışmalar sinırlıdır[13].

Statik deney koşullarında iribaşlar (Microhyla ornata) üzerinde yapılan bir araştırmada farklı beş ağır metalin (Hg, $\mathrm{Cd}, \mathrm{Cu}, \mathrm{Mn}, \mathrm{Zn})$ akut toksiteleri incelenmiş, test edilen ağır metallerin içinde en az toksik olanın $\mathrm{Zn}$ en fazla toksik olanı $\mathrm{Hg}$ olarak tespit edilmiştir [14]. Diğer bir araştırmada, Cd yeşil kurbağa, Pseudepidalea variabilis (Pallas, 1769) iribaşları üzerindeki akut toksik etkileri morfolojik ve histolojik bakımdan araştırılmış; P. variabilis iribaşlarının 96 saat boyunca $\mathrm{Cd}\left(0,1,5,10,25\right.$ ve $50 \mathrm{~nL}^{-}$ $\left.{ }^{1}\right)$ maruz bırakıldıklarında bu iribaşlardaki $\mathrm{LC}_{10}, \mathrm{LC}_{50}$ ve $\mathrm{LC}_{90}$ değerleri sirasıyla $26,98, \quad 35,35$ ve $46,31 \mathrm{~nL}^{-1}$ olarak hesaplanmıştır [15].

Doğal ortamdan toplanan farklı beş kurbağa iribaşının (Kaloula pulchra, Microhyla heymonsi, Fejervarya limnocharis, Hoplobatrachus rugulosus ve Microhyla pulchra) ağır metal konsantrasyonları; $\mathrm{Fe}>\mathrm{Cu}>\mathrm{Mn}>\mathrm{Zn}>$ $\mathrm{Cr}>\mathrm{Ni}>\mathrm{Pb}>\mathrm{Cd}>\mathrm{As}$ olarak bulunmuştur. Ağır metaller, su alımı, besin yolu ve epitelden doğrudan absorbe etme gibi farklı yollarla kurbağa ve iribaşlara girebilir. Solungaçlar, deri ve sindirim 
yolları, su çözeltisi ağır metal iki yaşamlılarda emilim potansiyeli olan organlardır [16].

Gümüş içeren nanopartikül (AgNP)' nin toksik etkileri Rana ridibunda 48 saatlik $\mathrm{LC}_{50}$ değerleri sirasıyla $0,055 \pm$ 0,004 ve $0,296 \pm 0,085 \mathrm{mg} / \mathrm{L}$ olarak hesaplanmıştır[17]. Bataklık kurbağası Pelophylax ridibundus üzerindeki ağır metal etkisini ve oksidatif stres enzimlerinde değişimi araştırıldığı bir çalışmada 18 ağır metal incelenmiş ( $\mathrm{Al}$, As, $\mathrm{Ba}, \mathrm{Ca}, \mathrm{Cd}, \mathrm{Co}, \mathrm{Cr}, \mathrm{Cu}, \mathrm{Fe}, \mathrm{Ga}, \mathrm{Hg}$, In, $\mathrm{Li}, \mathrm{Mn}, \mathrm{Ni}, \mathrm{Pb}, \mathrm{Sr}$ ve $\mathrm{Zn}$, ) bu ağır metallerin $\mathrm{Al}, \mathrm{Cd}, \mathrm{Co}, \mathrm{Cr}, \mathrm{Cu}, \mathrm{Fe}, \mathrm{Ga}, \mathrm{Hg}$ ve $\mathrm{Ni}$ konsantrasyonları karaciğerde en yüksek iken, $\mathrm{Ba}, \mathrm{Ca}, \mathrm{Li}, \mathrm{Mn}, \mathrm{Pb}, \mathrm{Sr}$ ve Zn'nin deride en yüksek olduğu belirlenmiştir [18].

Kurbağa türleri üzerinde morfolojik, genetik ve sistematik çalışmalar yapılmış olsa da $[19,20]$ iribaşlar üzerine çalışmalar nispeten azdır. Bu araştırmada, Türkiye' de uygun habitatlarda yaygın olarak bulunan ova kurbağası, Pelophylax ridibundus (Pallas, 1771 iribaşlarında, farklı ağır metal $(\mathrm{Pb}, \mathrm{Co}, \mathrm{Ba}, \mathrm{Cr})$ tuzları için 96 saatlik $\mathrm{LC}_{50}$ değerlerinin belirlenmesi amaçlanmıştır.

\section{Materyal ve Metot}

2017 Temmuz ayında Edirne merkezde bulunan geçici bir sulak alandan $\begin{array}{llll}(41.653671 & \mathrm{K}, & 26.595359 & \mathrm{D})\end{array} \quad P$. ridibundus (Pallas, 1771) iribaşları (toplam 240 adet; Gosner, 1960'a göre 20. evredeki); toplanarak $30 \times 60 \times 40 \mathrm{~cm}$ ebatlarındaki cam akvaryuma adaptasyon için konulmuştur [21]. Toplanan iribaşlar aktif karbondan geçmiş musluk suyu içeren $20 \mathrm{~cm}$ derinliğe sahip stok akvaryumda sürekli havalandırma doğal 1şık altında bırakılmıştır. Ova kurbağası iribaşların beslenmesinde ticari balık yemi kullanılmıştır [13]. Doğal ortamdan toplanan iribaşlar ortam şartlarına alıştırıldıktan sonra, statik deney şartlarında, 96 saat süreyle $0,1,10,50$, 100 ve $200 \mathrm{mg} / \mathrm{L}$ konsantrasyonlarında $\mathrm{Pb}, \mathrm{Co}, \mathrm{Ba}$ ve Cr'ye maruz bırakılmışlardır. Deneyde kullanılan

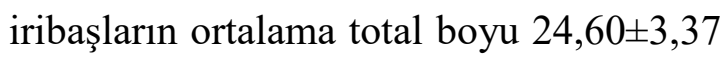
mm en küçük 17,89 mm en, büyük 30,47 $\mathrm{mm}$ ortalama sslak ağırlıkları ise 0,21 $\pm 0,06 \mathrm{~g}$ en küçük $0,07 \mathrm{~g}$ en büyük 0,29 g olarak ölçülmüştür. İribaş ölçümlerinde $\quad \pm 0.01 \quad \mathrm{~g}$ hassasiyetli elektronik terazi, uzunluk ölçümlerinde ise $\pm 0.01 \mathrm{~mm}$ hassasiyetli elektronik kumpas kullanılmıştır. Deneylerde kimyasal içeriği bilinen stok suyu kullanılmıştır

(Tablo1). 


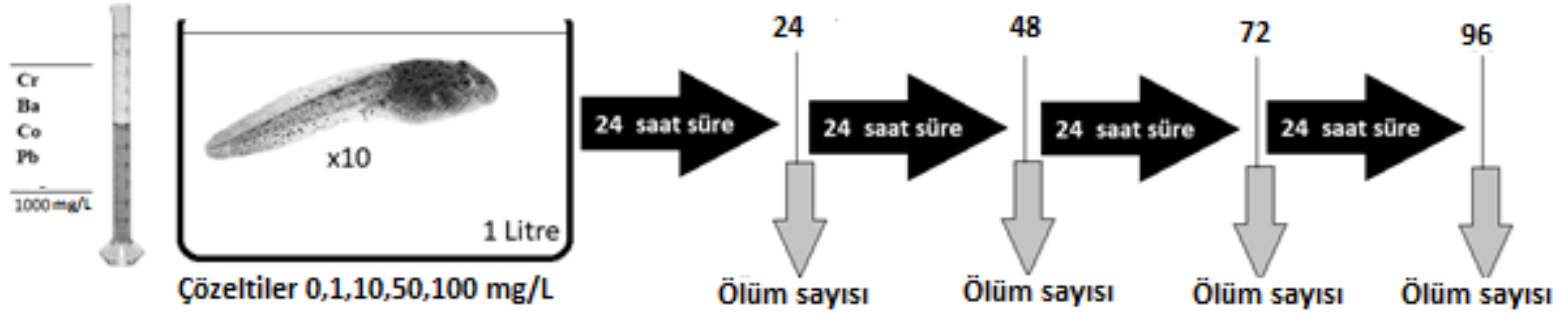

Şekil 1. Lethal doz deneylerinde (96 saatlik $L C_{50}$ deneyinde) izlenen algoritma.

Deneylerde kullanılan ağır metaller; metal tuzlarının $\left(\mathrm{BaCl}_{2} \times 2 \mathrm{H}_{2} \mathrm{O}, \quad \mathrm{MnSO}_{4} \times \mathrm{H}_{2} \mathrm{O}\right.$, $\left.\mathrm{CoCl}_{2} \times 6 \mathrm{H}_{2} \mathrm{O}, \quad \mathrm{N}_{2} \mathrm{OPb}, \quad \mathrm{K}_{2} \mathrm{CrO}_{4}\right) \quad 1000$ $\mathrm{mg} / \mathrm{L}$ 'lik stok çözeltilerinden seri sulandırma yolu hazırlanmıştır. Deneyler
1 litrelik PVC kaplar içinde (Şekil 1) 0 $\mathrm{mg} / \mathrm{L}, 1 \mathrm{mg} / \mathrm{L}, 10 \mathrm{mg} / \mathrm{L}, 50 \mathrm{mg} / \mathrm{L}, 100$ $\mathrm{mg} / \mathrm{L} \quad$ ve $200 \mathrm{mg} / \mathrm{L}$ ağır metal konsantrasyonlarında gerçekleştirilmiştir.

Tablo 1. Lethal doz deneylerde kullanılan stok suyu analiz sonuçları.

\begin{tabular}{|c|c|c|c|}
\hline Madde(birim) & Sonuç & Madde(birim) & Sonuç \\
\hline Florür (mg/L F) & $\mathbf{0 , 0 3}$ & Sülfür (mg/L S) & $\mathbf{0}$ \\
\hline Fosfat (mg/L $\left.\mathrm{PO}_{4}\right)$ & $\mathbf{0}$ & Aliminyum (mg/L AI) & $\mathbf{0}$ \\
\hline Bikarnonat $\left(\mathrm{mg} / \mathrm{L} \mathrm{CO}_{3}\right)$ & 85,4 & Amonyum $\left(\mathrm{mg} / \mathrm{L} \mathrm{NH}_{4}\right)$ & $\mathbf{0}$ \\
\hline Karbonat $\left.(\mathrm{mg} / \mathrm{L} \mathrm{CO})_{3}\right)$ & 4,8 & Kalsiyum (mg/L Ca) & 25,3 \\
\hline Klorür (mg/L CI) & 1,1 & Magnezyum (mg/L Mg) & 2,7 \\
\hline Nirat $\left(\mathrm{mg} / \mathrm{L} \mathrm{NO} \mathrm{NO}_{3}\right)$ & 1,6 & Potasyum (mg/L K) & $\mathbf{0}$ \\
\hline Nitrit $\left(\mathrm{mg} / \mathrm{L} \mathrm{NO}_{2}\right)$ & $\mathbf{0}$ & Sodyum (mg/L Na) & 6,3 \\
\hline Silisyum Dioksit (mg/L $\left.\mathrm{SiO}_{2}\right)$ & 9,1 & $\operatorname{Demir}^{+2}\left(\mathrm{mg} / \mathrm{L} \mathrm{Fe}{ }^{+2}\right)$ & $\mathbf{0}$ \\
\hline Sülfat $\left(\mathrm{mg} / \mathrm{L} \mathrm{SO}_{4}\right)$ & 8,0 & $\mathrm{pH}$ & 8,3 \\
\hline Toplam Sertlik (Fr) & 6,5 & & \\
\hline
\end{tabular}

Lethal doz deneyleri sirasinda bir cam çubukla iribaşlar nazikçe dokunarak hareketleri gözlenmiş deneylerde her 24 saatte bir ölüm sayıları kayıt edilmiştir. Bunun dıșında iribaşların davranışları gözlenerek kayıt edilmiştir.

Mortalite değerlerinin istatistiksel analizi SPSS (versiyon 10) yazılımı yapılmış [22]. $\mathrm{LC}_{50}$ (96 saat) ve\% 95 güven aralığg $\mathrm{LC}_{50}$ değerleri hesaplanmıştır.

\section{Sonuçlar}

Amfibiler çevredeki kimyasal kirleticilerden önemli ölçüde etkilenen bir gruptur. Özellikle yaşam döngülerinin erken safhalarında kimyasal kirliliğe maruz kalan canlı organizmalarda gelişim süresindeki gecikme ve mortalitede artış gözlenebileceği gibi morfolojik anormallikler (viseral ödem, aksiyal anomali ve kuyruk deformasyonu) de gözlenebilir. 
Rana pipiens, iribaşlarında (Gosner evresi 25-30) $\mathrm{Pb}$ (kurşun nitrat) maruz kalma, ölüm, büyümede yavaşlamaya, yüzme yeteneği azalması, lateral spinal eğriliği neden olduğu gözlenmiştir [23].

$\mathrm{Bu}$ araştırmada, lethal doz deneyleri sirasinda kontrol grubuna göre uygulama gruplarında davranış değişimleri belirlenmiştir. Uygulama gruplarında gözlenen davranış değişimleri, kontrol grubuna göre daha az hareketlilik, denge kayb1, normal grubundaki bireylerden farklı şekilde yüzme ve özellikle ölüm öncesi sırt üstü dönmedir.

Lethal deneyleri boyunca kontrol grubunda mortalite gözlenmemiştir. Deneylerde ağır metal konsantrasyonu iribaşlarda ölüm oranı ve sürelerinde farklıdır. 96 saatlik lethal doz deneyleri sonunda her bir ağır metal maruziyeti için zamana bağlı olarak tespit edilen mortalite sayıları Tablo 2 gösterilmiştir. Araştırılma tüm ağır metallerinde, konsantrasyonu ve süreye bağlı olarak iribaş mortalitesinde $\operatorname{art1ş}$ gözlenmiştir.

Tablo 2. Akut toksisite deneylerinde gözlenen mortalite sayllarl ve süreler.

\begin{tabular}{|c|c|c|c|c|c|c|c|}
\hline \multirow{2}{*}{\multicolumn{2}{|c|}{$\begin{array}{c}\text { Dozlar (g/mL) } \\
\text { Íribaş sayısı(n) }\end{array}$}} & Kontrol(0) & 1 & 10 & 50 & 100 & 200 \\
\hline & & 10 & 10 & 10 & 10 & 10 & 10 \\
\hline \multirow{4}{*}{ O: } & 24 saat & 0 & 0 & 0 & $7(\mathrm{Cr})$ & $\begin{array}{l}10(\mathrm{Cr}) \\
2(\mathrm{Co}) \\
5(\mathrm{~Pb})\end{array}$ & $\begin{array}{l}10(\mathrm{Cr}) \\
10(\mathrm{Co}) \\
10(\mathrm{~Pb})\end{array}$ \\
\hline & 48 saat & 0 & 0 & 0 & $1(\mathrm{Cr})$ & $\begin{array}{l}4(\mathrm{Co}) \\
1(\mathrm{Ba})\end{array}$ & $2(\mathrm{Ba})$ \\
\hline & 72 saat & 0 & 0 & 0 & 0 & $\begin{array}{l}2(\mathrm{Cr}) \\
2(\mathrm{Co})\end{array}$ & $2(\mathrm{Ba})$ \\
\hline & 96 saat & 0 & 0 & 0 & $1(\mathrm{Cr})$ & $\begin{array}{l}2(\mathrm{Cr}) \\
2(\mathrm{Co}) \\
4(\mathrm{Ba})\end{array}$ & $2(\mathrm{Ba})$ \\
\hline
\end{tabular}

Parantez içindeki rakamlar ağır metallere bağlı ölüm sayılarını göstermektedir•

Lethal doz deneyleri sonunda en yüksek $\mathrm{LC}_{50}$ değeri $\mathrm{Pb}(99,702 \mathrm{mg} / \mathrm{L})$ ile ve en düşük $\mathrm{LC}_{50}$ değeri $\mathrm{Cr}(30,002 \mathrm{mg} / \mathrm{L})$ hesaplanmıştır (Tablo 3). LC $_{50}$ değerlerine göre $\mathrm{Cr}, P$. ridibundus iribaşları için deneyde kullanılan ağır metal içinde en yüksek ölüm oranına sahiptir (Tablo 2). Bufo viridis $\mathrm{Cu} \mathrm{LC}_{50}$ değeri $0,058 \mathrm{mg} / \mathrm{L}$ olarak hesaplanmıștır [24]. Bakır sülfatın larval gelişim ve büyümede gerilemeye neden olduğunu göstermiştir. Boğa kurbağası (Rana catesbeiana) iribaşlarında yapılan bir çalışmada $\mathrm{Cr}$ ve $\mathrm{Pb}$ vücut ve kuyrukta farklı miktarda birikim yaptığı, $\mathrm{Mg}$, Se ve $\mathrm{Cd}$ atılımın farklılık gösterdiği belirlenmiştir [25]. 
$\mathrm{Bu}$ çalışmada akut toksik etkileri kapasitesinden kaynaklandı $\breve{g} 1$ araştırılan metal tuzlarının, hesaplanan $\mathrm{LC}_{50}$ değerlerinin geniş bir aralıkta yer düşünülmektedir. İribaşlarda kronik seviyede ağır metale maruz kalmanın olmasının çalışmada kullanılan iribaşların, ağır metalleri için farklı birikim ve atılım metamorfozu geciktirdiği ve davranış değişlerine yol açtığı gösterilmiştir [26].

Tablo 3. $\mathrm{Cr}$, $\mathrm{Co}, \mathrm{Ba}, \mathrm{Pb} 96$ saatlik $L C_{50}$ deney sonuçları (- hesaplanamamıştır).

\begin{tabular}{cccc}
\hline & $\begin{array}{c}\text { 96 saatlik LC } \\
(\mathbf{m g} / \mathbf{L})\end{array}$ & Alt limit & Üst limit \\
\hline $\mathbf{C r}$ & 30,002 & - & - \\
$\mathbf{B a}$ & 62,737 & 33,106 & 88,723 \\
$\mathbf{C o}$ & 69,783 & 47,975 & 96,599 \\
$\mathbf{P b}$ & 99,702 & 72,943 & 132,954 \\
\hline
\end{tabular}

P.ridibundus, Türkiyedeki en yaygın iki yaşamlı türlerinden biridir [27]. Farklı türdeki birçok iribaş, ağır metal kirliliğin biyoindikatörleri olarak kullanılmıştır [28]. Örneğin Rana hexadactyta iribaşlarındaki akut tokisistesi sırayla $\mathrm{Ag}>$ $\mathrm{Cu}>\mathrm{Hg}>\mathrm{As}>\mathrm{Zn}>\mathrm{Co}>\mathrm{Fe}>\mathrm{Pb}>\mathrm{Cr}$ olarak belirlenmiştir [29]. $\mathrm{Bu}$ araştırmada hesaplanan 96 saatlik $\mathrm{LC}_{50}$ değerleri arasında $\mathrm{Pb}>\mathrm{Co}>\mathrm{Ba}>\mathrm{Cr}$ siralaması olduğu bulunmuştur.

Ağır metallerin toksisitesindeki değişiklikler büyük ölçüde, test suyunun fiziko-kimyasal özellikleri, türlerin ve hayvanın yaşam evrelerinin ile ilgilidir [29]. $\mathrm{Bu}$ araştırmada fiziko-kimyasal yapısı belirlenmiş test suyu kullanılmıştır.

Deney şartlarında $P$. ridibundus iribaşları için en toksik metalin $\mathrm{Cr}$ olduğu belirlenmiştir. Kimyasal maddelerin etkilerinin değerlendirilmesinde bir canlı grubun tüm yaşam döngüsü dikkate alınmalıdır. Mevcut düzenlemeler, tüm canlı gruplarının tüm yaşam evreleri kapsamalı ve çevresel kontaminantlar (pestisit, ağır metal, sentetik kimyasal, endüstriyel atık vs.) için yürürlükte olan yasal limitler, canlıların biyolojik hassasiyetine ve içerisinde bulunduğu yaşam dönemine göre yeniden düzenlenmelidir.

\section{Kaynaklar}

[1]. Natale, G.S., N.G. Bassove A.E. Ronco, 2000, Effect of Cr (VI) on early life stages of three species of hylid frogs (Amphibia, Anura) from South America. Environmental toxicology. 15(5): p. 509512.

[2]. Boğa, A., S. Binokayve T. Özgünen, 2006, Çevre Kirliliğini Saptamada Kullanılan Yöntemler ve 
FETAX (Frog Embryos Teratogenesis Assay: Xenopus) Testi. 16: p. 13.

[3]. Dumont, J.N., T.W. Schultz, M.V. Buchananve G.L. Kao, 1983, Frog embryo teratogenesis assay: Xenopus (FETAX)—A short-term assay applicable to complex environmental mixtures, in Short-term bioassays in the analysis of complex environmental mixtures III. Springer. p. 393-405.

[4]. Chang, L., K. Rehulve A. Dudley, 3r (1973) Effects of methyl-mercuric chloride on Rana pipiens tadpoles. Environ Res. 8: p. 82-91.

[5]. Birdsall, C.W., C.E. Grueve A. Anderson, 1986, Lead concentrations in bullfrog Rana catesbeiana and green frog R. clamitans tadpoles inhabiting highway drainages. Environmental Pollution Series A, Ecological and Biological. 40(3): p. 233-247.

[6]. Berrill, M., S. Bertram, L. McGilliray, M. Kolohonve B. Pauli, 1994, Effects of low concentrations of forest-use pesticides on frog embryos and tadpoles. Environmental Toxicology and Chemistry. 13(4): p. 657-664.

[7]. Bridges, C.M.ve R.D. Semlitsch, 2000, Variation in pesticide tolerance of tadpoles among and within species of Ranidae and patterns of amphibian decline. Conservation Biology. 14(5): p. 1490-1499.

[8]. Nebeker, A., G. Schuytemave S. Ott, 1995, Effects of cadmium on growth and bioaccumulation in the Northwestern salamander Ambystoma gracile. Archives of Environmental Contamination and Toxicology. 29(4): p. 492-499.

[9]. Nebeker, A., G. Schuytemave S. Ott, 1994, Effects of cadmium on limb regeneration in the northwestern salamander Ambystoma gracile. Archives of Environmental Contamination and Toxicology. 27(3): p. 318-322.

[10]. Henle, K., 1981, A unique case of malformations in a natural population of the green toad (Bufo viridis) and its meaning for environmental politics. $\mathrm{Br}$. Herpetol. Soc. Bull. 4: p. 48-49.

[11]. Seven, T., B. Can, B.N. Darendeve S. Ocak, Hava ve Toprakta Ağır Metal Kirliliği. Ulusal Çevre Bilimleri Araştırma Dergisi. 1(2): p. 91-103.

[12]. Singh, P., M. Deyve S.N. Ramanujam, 2016, Bioaccumulation of heavy metals in anuran tadpoles: A study in Barak Valley, Assam. International Journal of Aquatic Biology. 4(3): p. 171.

[13]. Relyea, R.A., 2005, The lethal impacts of Roundup and predatory stress on six species of North American tadpoles. Archives of Environmental Contamination and Toxicology. 48(3): p. 351-357.

[14]. Shuhaimi-Othman, M., Y. Nadzifah, N. Umirahve A. Ahmad, 2012, Toxicity of metals to tadpoles of the common Sunda toad, Duttaphrynus melanostictus. Toxicological \& Environmental Chemistry. 94(2): p. 364376.

[15]. Gürkan, M., A. Çetinve S. Hayretdag, 2014, Acute toxic effects of cadmium in larvae of the green toad, Pseudepidalea variabilis (Pallas, 1769)(Amphibia: Anura). Archives of Industrial Hygiene and Toxicology. 65(3): p. 301-309.

[16]. Intamat, S., U. Phoonaploy, M. Sriuttha, B. Tengjaroenkulve L. Neeratanaphan, 2016, Heavy metal accumulation in aquatic animals around the gold mine area of Loei province, 
Thailand. Human and Ecological Risk Assessment: An International Journal. 22(6): p. 1418-1432.

[17]. Johari, S., I. Sourinejad, S. Asgharive N. Barsch, 2015, Toxicity comparison of silver nanoparticles synthesized by physical and chemical methods to tadpole (Rana ridibunda). Caspian Journal of Environmental Sciences. 13(4): p. 383-390.

[18]. Borković-Mitić, S.S., M.D. Prokić, I.I. Krizmanić, J. Mutić, J. Trifković, J. Gavrić, S.G. Despotović, B.R. Gavrilović, T.B. Radovanovićve S.Z. Pavlović, 2016, Biomarkers of oxidative stress and metal accumulation in marsh frog (Pelophylax ridibundus). Environmental Science and Pollution Research. 23(10): p. 9649-9659.

[19]. Bodenheimer, F.S., 1944, Introduction into the knowledge of the Amphibia and Reptilia of Turkey. Marmara Basemevi.

[20]. Çiçek, K.ve A. Mermer, 2007, Food composition of the marsh frog, Rana ridibunda Pallas, 1771, in Thrace. Turkish Journal of Zoology. 31(1): p. 83-90.

[21]. Gosner, K.L., 1960, A simplified table for staging anuran embryos and larvae with notes on identification. Herpetologica. 16(3): p. 183-190.

[22]. Jia, C., 2006, Calculated the LC50 of pesticides using SPSS software. Chin. Bull. Entomol. 43: p. 414-417.

[23]. Chen, T.H., J.A. Grossve W.H. Karasov, 2006, Sublethal effects of lead on northern leopard frog (Rana pipiens) tadpoles. Environmental toxicology and chemistry. 25(5): p. 1383-1389.

[24]. Gürkan, M.ve S. Hayretdağ, 2012, Morphological and histological effects of copper sulfate on the larval development of green toad, Bufo viridis. Turkish Journal of Zoology. 36(2): p. 231-240.

[25]. Rowe, C.L., O.M. Kinney, R.D. Nagleve J.D. Congdon, 1998, Elevated maintenance costs in an anuran (Rana catesbeiana) exposed to a mixture of trace elements during the embryonic and early larval periods. Physiological Zoology. 71(1): p. 27-35.

[26]. Lefcort, H., R. Meguire, L. Wilsonve W. Ettinger, 1998, Heavy metals alter the survival, growth, metamorphosis, and antipredatory behavior of Columbia spotted frog (Rana luteiventris) tadpoles. Archives of Environmental Contamination and Toxicology. 35(3): p. 447-456.

[27]. Yilmaz, N., B. Kutrup, U. Cobanogluve Y. Özoran, 2005, Age determination and some growth parameters of a Rana ridibunda population in Turkey. Acta Zoologica Academiae Scientiarum Hungaricae. 51(1): p. 67-74.

[28]. Loumbourdis, N., P. Kyriakopoulou-Sklavounouve G. Zachariadis, 1999, Effects of cadmium exposure on bioaccumulation and larval growth in the frog Rana ridibunda. Environmental Pollution. 104(3): p. 429433.

[29]. Khangarot, B.ve P. Ray, 1987, Sensitivity of toad tadpoles, Bufo melanostictus (Schneider), to heavy metals. Bulletin of environmental contamination and toxicology. 38(3): p. 523-527. 